\title{
Amorphous to Tetragonal Zirconia Nanostructures and Evolution of Valence and Core Regions
}

\author{
Sesha Vempati, ${ }^{* \dagger}{ }^{\dagger}$ Fatma Kayaci-Senirmak, ${ }^{\dagger, \dagger}$ Cagla Ozgit-Akgun, ${ }^{\dagger,+}$ Necmi Biyikli, ${ }^{\dagger, \ddagger}$ and Tamer Uyar ${ }^{*}$, , \\ ${ }^{\dagger}$ UNAM-National Nanotechnology Research Centre, and ${ }^{\ddagger}$ Institute of Materials Science \& Nanotechnology, Bilkent University, \\ Ankara 06800, Turkey
}

\section{Supporting Information}

\begin{abstract}
In this report, we study the evolution of valence band (VB) structure during a controlled amorphous to tetragonal transformation of $\mathrm{ZrO}_{2}$ core-shell nanostructures fabricated from electrospun nanofiber template (at 130,200 , and $250{ }^{\circ} \mathrm{C}$ ). Shell- $\mathrm{ZrO}_{2}$ was formed with atomic layer deposition. X-ray diffraction and transmission electron microscopy are employed to unveil the transformation of amorphous to crystalline structure of $\mathrm{ZrO}_{2} . \mathrm{O} 1 \mathrm{~s}$ core-level spectra indicated chemisorbed oxygen $\left(\mathrm{O}_{\mathrm{Ch}}\right)$ of almost invariant fraction for the three samples. $\mathrm{Zr} 3 \mathrm{~s}$ level suggested that the sample deposited at $130{ }^{\circ} \mathrm{C}$ has depicted a peak at relatively higher binding energy. Analyses on $\mathrm{Zr}$ $3 \mathrm{~d}$ spectra indicated the presence of metallic- $\mathrm{Zr}\left(\mathrm{Zr}^{+\zeta}, 0 \leq|\zeta|<4\right)$, the fraction of which decreases with increasing template temperature. VB region is analyzed until $\sim 64 \mathrm{eV}$ below the Fermi level $\left(E_{\mathrm{F}}\right)$. The region close to $E_{\mathrm{F}}$ depicted features that are dissimilar to the literature. This discrepancy is explained on the basis of the analyses from $\mathrm{O} 1 \mathrm{~s}, \mathrm{Zr} 3 \mathrm{~d}$, and $\mathrm{Zr} 4 \mathrm{p}$ levels including hybridization of orbitals from chemisorbed species. These levels were analyzed in terms of peak characteristics such as spectral position, area under the peak, etc. The results of this study would enhance the understanding of the evolution of various bands in the presence of $\mathrm{O}_{\mathrm{Ch}}$ and changes to the crystallinity enabling the functionalities that are not available in the single-phase $\mathrm{ZrO}_{2}$.
\end{abstract}

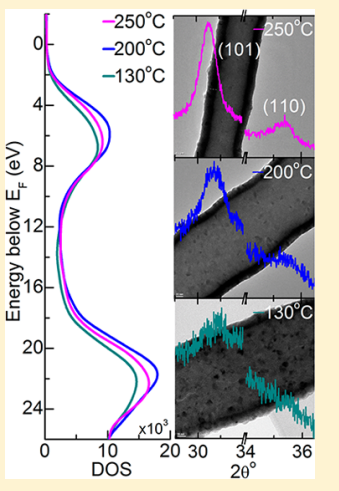

\section{INTRODUCTION}

Significant need for high- $\kappa$ materials leads to the research on the crystallinity controlled synthesis ${ }^{1,2}$ and subsequent understanding of electronic structure of d-block metal oxides such as $\mathrm{ZrO}_{2}$ and $\mathrm{HfO}_{2}{ }^{2-5}$ These materials are, in general, used in the form of relatively thicker films, however, capacitively equivalent although better gate dielectrics (better potential barriers to both holes and electrons). ${ }^{6}$ Often $\mathrm{ZrO}_{2}$ and $\mathrm{HfO}_{2}$ were discussed together in the literature ${ }^{5,7}$ by giving their comparable properties and characteristics. However, $\mathrm{ZrO}_{2}$ is quite an interesting material due to a range of application potentials. ${ }^{8-11}$ For instance, yittria stabilized $\mathrm{ZrO}_{2}$ is employed in thermal barrier coatings ${ }^{8}$ (note the other lower valence stabilizers $\mathrm{CaO}, \mathrm{MgO}$ ), ${ }^{9}$ catalysis, ${ }^{10,11}$ etc. Band structure calculations on $\mathrm{ZrO}_{2}$ suggest that the three polymorphs (tetragonal, ${ }^{9,12}$ monoclinic, ${ }^{12}$ or cubic $^{9}$ ) show similar features, with minor differences in the width of the band and the band gap. ${ }^{5,13}$ Note the experimental band gaps of $\mathrm{ZrO}_{2}$ are in the range of $5-6 \mathrm{eV}$ depending on the synthesis $^{14}$ and phase (tetragonal > monoclinic > cubic). ${ }^{5}$ Typically, as-deposited $\mathrm{ZrO}_{2}$ thin film is amorphous ${ }^{15}$ while nanocrystallites are formed during a high temperature annealing $(\sim 1000 \mathrm{~K})$. However, deposition techniques such as atomic layer, chemical vapor, physical vapor, ${ }^{14}$ etc., produce thin films of varying quality and phase compositions. In these synthesis techniques, the formation of intrinsic crystal defects such as oxygen vacancies $\left(\mathrm{V}_{\mathrm{O}}\right.$ 's) and oxygen interstitials $\left(\mathrm{O}_{\mathrm{i}}\right.$ 's) are unavoidable. In cubic- $\mathrm{ZrO}_{2}$, low diffusion barriers for $\mathrm{V}_{\mathrm{O}}$ 's and $\mathrm{O}_{\mathrm{i}}$ 's were identified within $2600-2980 \mathrm{~K}^{16-18}$ The formation energy of $\mathrm{V}_{\mathrm{O}}$ 's is found to decrease in an unrecognized $\mathrm{ZrO}_{2}$ due to tensile strain. ${ }^{18}$ Furthermore, the tensile strain transforms $\mathrm{ZrO}_{2}$ from cubic fluorite to the orthorhombic columbite. ${ }^{18}$

Given the fact that the chemical and physical properties including the electronic structure are influenced by the synthesis process, 9,14 we have studied the valence band (VB) and corelevel ionic states of $\mathrm{Zr}$ and $\mathrm{O}$ in tetragonal- $\mathrm{ZrO}_{2}$ core-shell nanostructures. Core-shell nanostructures were prepared by combining electrospinning and atomic layer deposition (ALD), where the former produces the core-polymer nanofiber (template) while the latter forms conformal $\mathrm{ZrO}_{2}$ coating. By controlling the temperature of the template, a gradual transition is evident from amorphous to tetragonal $\mathrm{ZrO}_{2}$ at relatively higher temperatures. Apart from this clear transition, the presence of metallic $\mathrm{Zr}$ on the surface including $\mathrm{V}_{\mathrm{O}}$ 's influenced the lattice parameters and of course the electronic structure of $\mathrm{ZrO}_{2}$. Significantly, chemisorbed ions on the surface and at the defect sites (e.g., $\mathrm{V}_{\mathrm{O}}$ 's) influenced the electronic structure considerably. ${ }^{13}$ The $\mathrm{ZrO}_{2}$ and metallic-Zr homocombination together with lattice strain can potentially vary the electronic structure leading to various applications such as fast-ion conductors. ${ }^{18} \mathrm{We}$ may expect functionalities that are not available in the singlephase $\mathrm{ZrO}_{2}$. Essentially, this study might help to unveil and harness the influence of intertwined though crucial objects such as crystallinity, defects, lattice strain, and chemisorbed species in determining the electronic structure.

Received: August 13, 2015

Revised: September 16, 2015

Published: September 16, 2015 


\section{RESULTS AND DISCUSSION}

Figure 1 shows the schematic diagram to fabricate core-shell nanostructures. In step 1 , the electrospinning process is

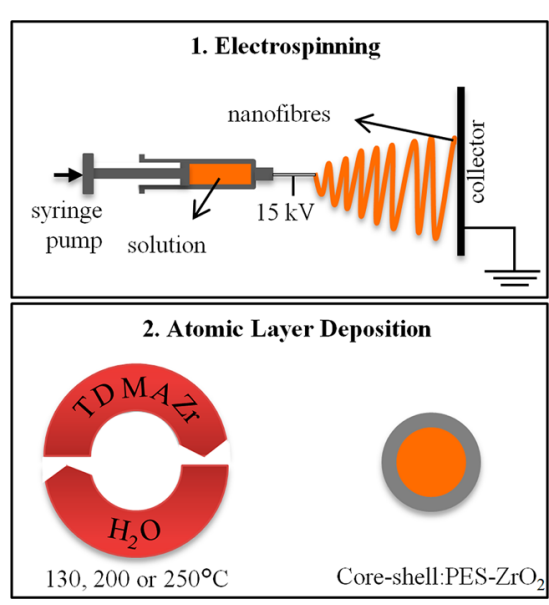

Figure 1. Cartoon depicting the electrospinning and subsequent ALD process to fabricate core-shell $\mathrm{PES}-\mathrm{ZrO}_{2}$ nanostructure at three different substrate temperatures. TDMAZr, tetrakis (dimethylamido) zirconium; and PES, polyether sulfone.

employed to prepare the nanofibers, which act as a template and form the "core" structure. In step 2, ALD is employed for three different substrate temperatures, 130,200 , or $250^{\circ} \mathrm{C}$. Refer to the Experimental Section for the full description of these processes. Scanning electron microscope images of the samples are shown in Figure S1 for polyether sulfone (PES) nanofibers along with the three core-shell $\mathrm{ZrO}_{2}$ samples. We can see that the structural integrity of the fibers was sustained after the ALD process. $^{19}$

Transmission electron microscope (TEM) images of 130, 200, and $250{ }^{\circ} \mathrm{C}$ samples are shown in Figure $2 \mathrm{a}-\mathrm{c}$, respectively.

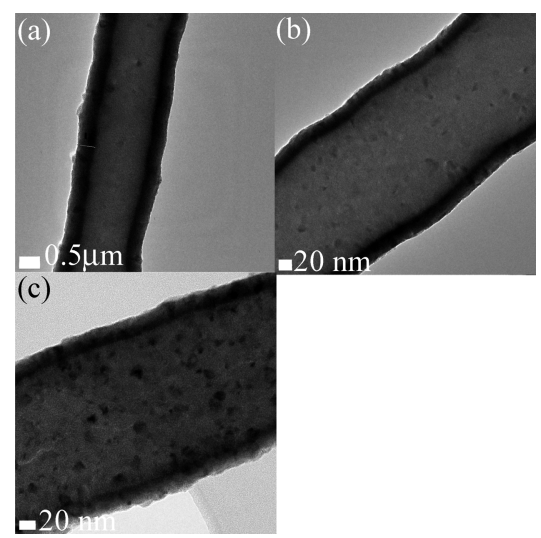

Figure 2. TEM images of core-shell PES- $\mathrm{ZrO}_{2}$ nanofibers: (a) $130{ }^{\circ} \mathrm{C}$, (b) $200^{\circ} \mathrm{C}$, and (c) $250^{\circ} \mathrm{C}$.

Conformal and uniform coating can be observed for all samples. Because the fiber structure did not disintegrate, the compatibility between the ALD precursors and the polymer core is notable. ${ }^{19}$ The $\mathrm{ZrO}_{2}$ shell thickness is $\sim 400, \sim 20$, and $\sim 22 \mathrm{~nm}$ for 130, 200, and $250{ }^{\circ} \mathrm{C}$ samples, respectively. For the set parameters, the growth rates in the dynamic mode on planar $\mathrm{Si}$ are 1.02 and 0.98 $\AA /$ cycle at 200 and $250{ }^{\circ} \mathrm{C}$ (Ultratech/Cambridge Nanotech Inc.). A large deviation in the shell-thickness of the $130{ }^{\circ} \mathrm{C}$ sample from others can be described as follows. Although the precursors were purged as long as exposed, this duration is insufficient at $130{ }^{\circ} \mathrm{C}$. This results in relatively high residual precursor molecules that react in the gas phase (CVD-like growth). Consequently, a thicker $\mathrm{ZrO}_{2}$ layer is observed for the $130{ }^{\circ} \mathrm{C}$ sample. In an ideal ALD process on planar substrates, the duration of exposure should not affect the deposition rate. However, in the case of substrates with a high surface area to volume ratio, such as present, the deposition rate is limited by the diffusion of precursor molecules, in which case, diffusion is controlled by the purge time (lower value, less thickness). Keeping this aside, we wish to explore the surface electronic structure. Unless the thickness of the layer is in the quantum confinement region, ${ }^{20}$ the surface nature is expected to be well comparable across the above range of thicknesses by giving the mean free path of the escaping photoelectrons. Furthermore, the grainy nature of the coating increases with increasing temperature. The $130^{\circ} \mathrm{C}$ sample has a smooth texture, indicating largely amorphous nature of the sample. As the substrate temperature increases $\left(200{ }^{\circ} \mathrm{C}\right)$, the grains start evolving, suggesting formation of single crystals in various orientations. For the 250 ${ }^{\circ} \mathrm{C}$ sample, the density of grains is increased, which we will see to corroborate with the results from X-ray diffraction (XRD).

$\mathrm{XRD}$ patterns from the three $\mathrm{ZrO}_{2}$ samples are shown Figure $3 \mathrm{a}$. It can be seen that the reflections correspond to the tetragonal

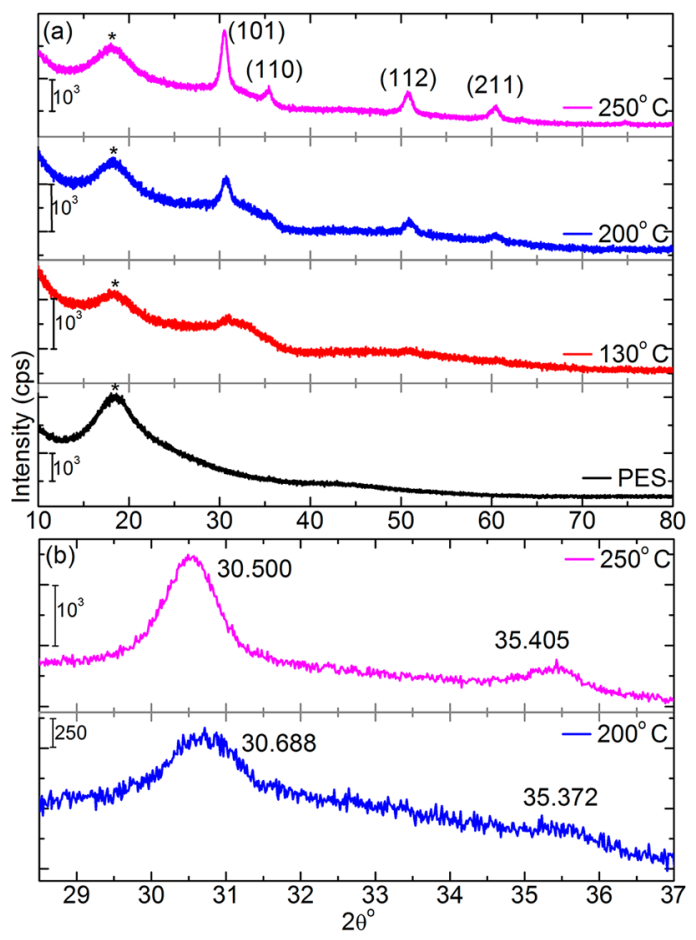

Figure 3. XRD patterns for the three samples: (a) reflections are annotated, which correspond to tetragonal lattice. * denotes the diffraction peak from PES. (b) $2 \theta$ region $28.5-37^{\circ}$ is magnified depicting the (101) and (110) planes and angular location in degrees.

phase of $\mathrm{ZrO}_{2}$. The phase diagram of $\mathrm{ZrO}_{2}$ consists of three stable polymorphs (tetragonal, ${ }^{9,12}$ monoclinic, ${ }^{12}$ or cubic $^{9}$ ) at atmospheric pressure depending on the growth condition. ${ }^{9}$ Although the most stable and preferential phase is monoclinic, the tetragonal phase has been observed in nanoparticles or ultrathin films, ${ }^{12}$ which is the case here. For the $130^{\circ} \mathrm{C}$ sample, apart from a very broad peak corresponding to PES (denoted 
with $*)$, the signature from (101) and (110) reflections can be seen. When the substrate temperature is increased to $200{ }^{\circ} \mathrm{C}$, the above two peaks start to take shape in addition to (112) and (211) reflections. A further increase in the temperature $\left(250^{\circ} \mathrm{C}\right)$ shows well-defined and clearly distinguishable peaks when compared to the other two samples (see the relative intensities of the peaks). These results were well corroborated with the TEM observations. A closer inspection of the $2 \theta$ range $28.5-37^{\circ}$ (Figure $3 b$ ) suggests a shift of (101) and (110) reflections (130 ${ }^{\circ} \mathrm{C}$ derived sample is not considered for this analysis). The feature that is seen between $\sim 28-37^{\circ}$ range is quite close to that in the literature (see Figure $2 \mathrm{a}$ in ref 1 while noting the similarity in the preparation). The angular positions of (101) and (110) yield the following lattice parameters for tetragonal structure: $a=$ $3.585 \AA, c=5.091 \AA$ for $250{ }^{\circ} \mathrm{C}$ sample, while for $200{ }^{\circ} \mathrm{C}$ sample, $a=3.553 \AA$ and $c=5.252 \AA$. As the substrate temperature is increased, the $a$ value is increased $(\sim 0.9 \%)$, while in contrast the $c$ value is decreased $(\sim 3 \%)$ with reference to the $200{ }^{\circ} \mathrm{C}$ sample. Because of the relatively lower temperature growth, intrinsic lattice defects can be expected during growth.

$\mathrm{O}$ 1s spectra along with peak deconvolution are shown in Figure 4 for the three $\mathrm{ZrO}_{2}$ core-shell samples. The spectral

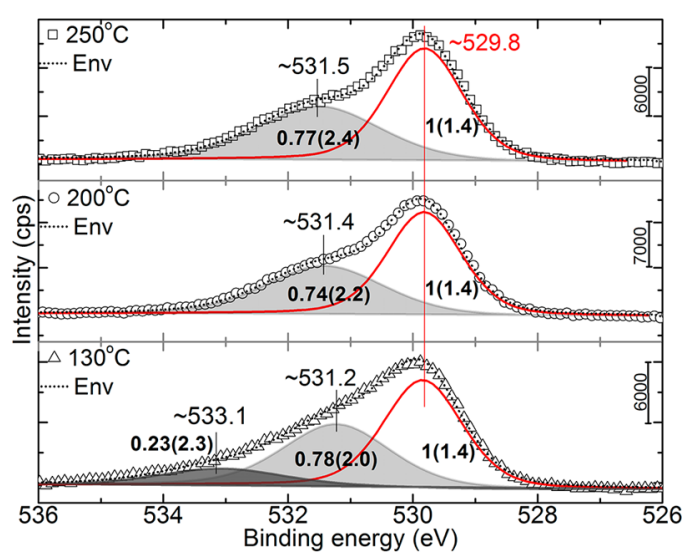

Figure 4. $\mathrm{O}$ 1s spectra from the three core-shell $\mathrm{ZrO}_{2}$ samples. The spectral position (in $\mathrm{eV}$ ) and area ratio are annotated on the image, while fwhm (in $\mathrm{eV}$ ) is parenthesized.

positions (in $\mathrm{eV}$ ) and area ratios were annotated on the image. Shown in parentheses are fwhm ${ }^{21}$ values in $\mathrm{eV}$. The major peak $(\sim 529.8 \mathrm{eV})$ corresponds to the tetragonally coordinated oxygen in $\mathrm{ZrO}_{2} .{ }^{22}$ It is notable that the fwhm ${ }^{21}$ of the O-peak corresponding to $\mathrm{ZrO}_{2}$ sustained its width $(\sim 1.4 \mathrm{eV})$ for all deposition temperatures. The shoulder at the higher binding energy region is explicit in all cases. This shoulder consists of a second major peak centered between 531.2 and $531.5 \mathrm{eV}$. Furthermore, the $\mathrm{ZrO}_{2}$ sample deposited at $130{ }^{\circ} \mathrm{C}$ depicted a third peak at $\sim 533.1 \mathrm{eV}$ in contrast to the other two samples. The peak centered at $531.5 \pm 0.1 \mathrm{eV}$ is associated with $\mathrm{O}^{x-}$ ions $(x<$ 2 ), while that at $532.5 \pm 0.1 \mathrm{eV}$ is typically ascribed to $-\mathrm{OH}$ groups, chemisorbed oxygen $\left(\mathrm{O}_{\mathrm{Ch}}\right)$, or dissociated oxygen, ${ }^{20,23}$ or oxygen in $-\mathrm{CO}^{24,25}$ The minor peak centered at $\sim 533.1 \mathrm{eV}$ corresponds to oxygen in $\mathrm{H}_{2} \mathrm{O} .{ }^{22}$ It is notable that the density of this $\mathrm{O}_{\mathrm{Ch}}$ did not vary significantly across the three samples. The peak position and fwhm ${ }^{21}$ values of $\mathrm{O}_{\mathrm{Ch}}$ are seen to increase as the temperature of the template increases. The spectral positions of all peaks match with that in the literature. ${ }^{22} \mathrm{O}_{\mathrm{Ch}}$, in general, occupies $\mathrm{V}_{\mathrm{O}}$ 's on the surface of the lattice, while these defects are found to enhance the catalytic activity, for example, in $\mathrm{ZnO}$ nanostructures. ${ }^{20,23}$ Furthermore, due to the relatively lower temperature of the ALD growth process, the presence of the $-\mathrm{OH}$ group is expected.

The $\mathrm{Zr} 3$ s spectral region is shown in Figure S2 for the three $\mathrm{ZrO}_{2}$ core-shell samples. The energetic positions are annotated on the image and match with the literature. ${ }^{22}$ The spectral positions of the peaks are as follows: $433.2,432.6$, and $432.8 \mathrm{eV}$ for 130,200 , and $250{ }^{\circ} \mathrm{C}$ samples, respectively. $\mathrm{Zr}$ 3s from $\mathrm{ZrO}_{2}$ appears at $\sim 432.7 \mathrm{eV}$ as noted in the literature. ${ }^{22}$ It is interesting to note that the $130{ }^{\circ} \mathrm{C}$ sample has shown a peak at relatively higher binding energy than the other two samples. The blue shift of $\sim 0.6 \mathrm{eV}$ may be due to a slightly different/increased ionic environment. Most probably this would have occurred due to the $\mathrm{H}_{2} \mathrm{O}$ on the surface of the $130^{\circ} \mathrm{C}$ samples. When the deposition temperature increases from 200 to $250^{\circ} \mathrm{C}$, an increase $(\sim 0.2 \mathrm{eV})$ in the binding energy is apparent. This slight blue shift is consistent with the results from $\mathrm{O}_{\mathrm{Ch}}$ densities from $\mathrm{O} 1 \mathrm{~s}$ spectra, which increase from the 200 to $250{ }^{\circ} \mathrm{C}$ sample. The fwhm ${ }^{21}$ values decrease with increasing temperature of the substrate, which suggests a well-defined hybridization in $\mathrm{ZrO}_{2}$ lattice.

The $\mathrm{Zr} 3 \mathrm{~d}$ spectral region is shown in Figure 5 for the three $\mathrm{ZrO}_{2}$ core-shell samples. The photoemission line majorly

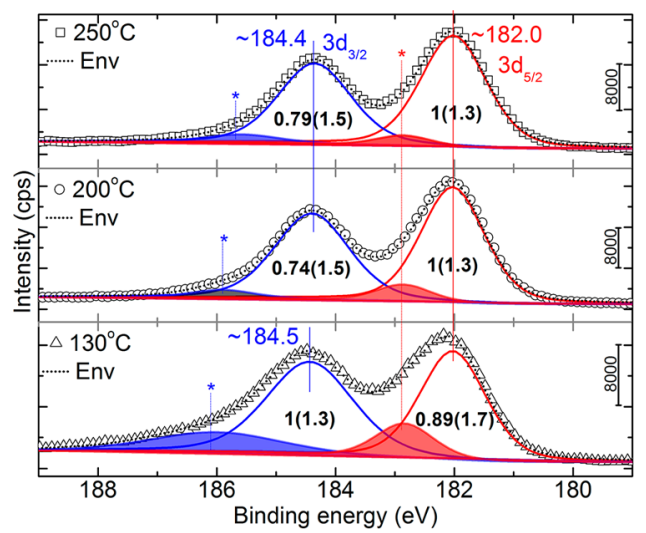

Figure 5. $\mathrm{Zr} 3 \mathrm{~d}$ spectra from the three samples. The spectral position (in $\mathrm{eV})$ and area ratio are annotated on the image, while fwhm is parenthesized (in $\mathrm{eV}$ ).

depicted $\mathrm{Zr} 3 \mathrm{~d}$ spin orbit splitting $\left(3 \mathrm{~d}_{5 / 2}\right.$ and $\left.3 \mathrm{~d}_{3 / 2}\right)$, the spectral positions of which match that of the literature. ${ }^{22}$ The differences in the chemical environment are, in general, reflected in the characteristics of the doublet including splitting. Here, the splitting remained constant for all samples, in contrast to their characteristics $\left(\right.$ see $f w h m^{21}$ ). To appropriately compare the area ratios across the three samples, we have taken the secondary ratio $\left(\operatorname{area}_{3 \mathrm{~d}_{5 / 2}} / \operatorname{area}_{3 \mathrm{~d}_{3 / 2}}\right)$ yielding $0.89,1.35$, and 1.27 for 130,200 , and $250{ }^{\circ} \mathrm{C}$. These values suggest an almost increasing $3 \mathrm{~d}_{5 / 2}$ contribution with substrate temperature, which is nothing but an increasing degree of tetragonal coordination. This is consistent with the results from the XRD and TEM. The spin orbit splitting of $3 \mathrm{~d}$ orbital is found to be $\sim 2.4 \mathrm{eV}$ in line with the literature value of $2.38 \mathrm{eV}$, which was grown at $300{ }^{\circ} \mathrm{C}$ in ALD. ${ }^{6}$ Interestingly, all samples exhibit a shoulder at higher binding energy than $3 \mathrm{~d}_{3 / 2}$. This shoulder is attributed to metallic zirconium with $\mathrm{Zr}^{+\zeta},|\zeta|<4 .{ }^{26}$ Reduced zirconium combined partially with the oxidant during the ALD process. ${ }^{26}$ In ref $26, \mathrm{Ji}$ et al. employed a single peak in the deconvolution of $3 \mathrm{~d}$ core level. However, $\mathrm{Zr}$ atoms depict the spin-orbit splitting irrespective of the oxidation state, that is, $3 d_{5 / 2}$ and 
$3 \mathrm{~d}_{3 / 2} \cdot{ }^{22,27,28}$ Hence, it is appropriate to consider a doublet with reference to this shoulder as shown in Figure 5 (denoted with *, shaded peaks). The characteristics ${ }^{21}$ of the doublet from metallic like- $\mathrm{Zr}\left(\mathrm{Zr}^{+\zeta}\right)$ are tabulated in Table 1. We believe that absolute

Table 1. Characteristics of Peaks Denoted with “*” on $\mathrm{Zr}$ 3d Core-Level $\left(\mathrm{Zr}^{+\zeta}\right)$ Spectra in Figure 5

\begin{tabular}{cccccccc} 
& \multicolumn{3}{c}{$* 3 \mathrm{~d}_{5 / 2}$} & & \multicolumn{3}{c}{$* 3 \mathrm{~d}_{3 / 2}$} \\
\cline { 2 - 5 } \cline { 7 - 8 } $\begin{array}{c}\text { sample } \\
\left({ }^{\circ} \mathrm{C}\right)\end{array}$ & $\begin{array}{c}\text { peak } \\
\text { position } \\
(\mathrm{eV})\end{array}$ & $\begin{array}{c}\text { area } \\
\text { ratio }\end{array}$ & $\begin{array}{c}\text { fwhm } \\
(\mathrm{eV})\end{array}$ & & $\begin{array}{c}\text { peak } \\
\text { position } \\
(\mathrm{eV})\end{array}$ & $\begin{array}{c}\text { area } \\
\text { ratio }\end{array}$ & $\begin{array}{c}\text { fwhm } \\
(\mathrm{eV})\end{array}$ \\
130 & 182.9 & 0.25 & 1.15 & & 186.1 & 0.31 & 2.57 \\
200 & 182.9 & 0.12 & 1.08 & & 185.8 & 0.06 & 1.19 \\
250 & 182.8 & 0.06 & 1.08 & & 185.7 & 0.06 & 1.42 \\
\hline
\end{tabular}

spectral positions of these peaks, however, cannot be attributed to any specific ionic state, due to the finite uncertainty involved in deconvolution in the background of complex envelop of density of states. Hence, these peaks are referred to $\mathrm{Zr}^{+\zeta}, 0 \leq|\zeta|<4$, with varying $(2.8-3.2 \mathrm{eV})$ spin orbit splitting. From Table 1 , it is also noted that the relative area ratio and $\mathrm{fwhm}^{21}$ appeared to decrease as the temperature of the template increases. It has been recently shown that the formation of $\mathrm{Zr}^{1+}, \mathrm{Zr}^{2+}$, and $\mathrm{Zr}^{3+}$ as nonequilibrium oxidation states is possible in addition to $\mathrm{Zr}^{4+}$ in the stoichiometric $\mathrm{ZrO}_{2}{ }^{29}$ Hence, assigning $0 \leq|\zeta|<4$ is appropriate. Moreover, we would like to draw a similarity between this metallic $3 d$ doublet of $\mathrm{Zr} 3 \mathrm{~d}$ with that of $\mathrm{Zn} 2 \mathrm{p}$ from a d-block metal oxide, $\mathrm{ZnO} .^{20}$ In the case of $\mathrm{ZnO}$, the presence of such a high energy doublet is attributed to intrinsic defects such as interstitial zinc. These defects were part of a cause for the lattice strain in $\mathrm{ZnO}$. However, in the present context, further characterization is warranted to confirm the presence of $\mathrm{Zr}^{+\zeta}$ in the interstitial site as the latter can be a substrate effect. As mentioned in the context of XRD, the lattice strain can be attributed to the $\mathrm{Zr}^{+\zeta}$ in the interstitial sites. Furthermore, the influence of deposition parameters (refer to the Experimental Section) on a substrate of high surface area to volume ratio can be reflected in the properties: for instance, (i) thickness of the $\mathrm{ZrO}_{2}$ shell (Figure 2 and explanation therein), and (ii) effectiveness of the reduction of $\mathrm{Zr}$ (presence of $\mathrm{Zr}^{+\zeta}, 0 \leq|\zeta|<4$ ).

The VB region is shown from 64 to $-5 \mathrm{eV}$ in Figure 6. The region from 64 to $40 \mathrm{eV}$ consists of hybridized/deeper valence states; for example, see the $\mathrm{Zr} 4 \mathrm{~s}$ state as annotated on the image at $\sim 53 \mathrm{eV}$. $\mathrm{Zr} 4 \mathrm{~s}$ seemed invariant for all samples within the present energy resolution. The peak centered at $\sim 30.8 \mathrm{eV}$ is attributed to $\mathrm{Zr} 4 \mathrm{p}$, which is expected to be a clear doublet and relatively sharp as seen by Sayan et al. ${ }^{6}$ However, we did not observe it to be as explicit as shown in the literature. ${ }^{6}$ In any case, this peak is deconvoluted as a doublet for all samples. The spin orbit splitting of $4 \mathrm{p}$ orbital is found to vary within $1.66-2.8 \mathrm{eV}$ in comparison with $1.57 \mathrm{eV}$ (grown at $300^{\circ} \mathrm{C}$ in ALD). ${ }^{6}$ The larger splitting would have originated from very different effects from the crystal field. The peak centered $\sim 21.9 \mathrm{eV}$ consists of two components, while the energetic position of the low energy component is invariant for all cases. The higher energy component is almost invariant $(\sim 21.7 \mathrm{eV})$ for 130 and $250{ }^{\circ} \mathrm{C}$ samples, while for the $200{ }^{\circ} \mathrm{C}$ sample it has blue-shifted to $\sim 23.1$ $\mathrm{eV}$. Valence edge regions that we have experimentally observed are quite different from that of the literature. ${ }^{5,6}$ However, we have deconvoluted into two peaks, which in fact turned out to be majorly a single peak, while the second component is quite broad and possesses almost a negligible area (denoted with * in Figure

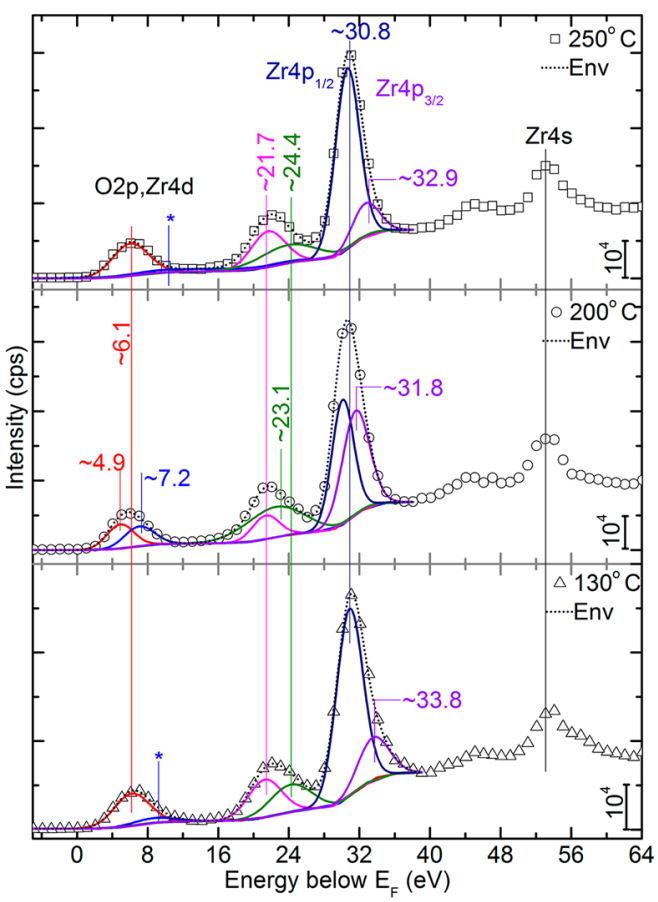

Figure 6. Valence band spectra from the three core-shell samples. The spectral position (in $\mathrm{eV}$ ) and area ratio are annotated on the image.

6) for the 130 and $250{ }^{\circ} \mathrm{C}$ samples. In contrast, the $200{ }^{\circ} \mathrm{C}$ sample depicted the two peaks at $\sim 4.9$ and $\sim 7.2 \mathrm{eV}$. In the following, we have compared our results with those of simulation $^{5}$ and experimental ${ }^{6}$ profiles from literature. ${ }^{5,6}$

We start our discussion with the profiles observed from the literature (Figure 7a). ${ }^{5,6}$ Data curves (i), (ii), and (iii) were taken

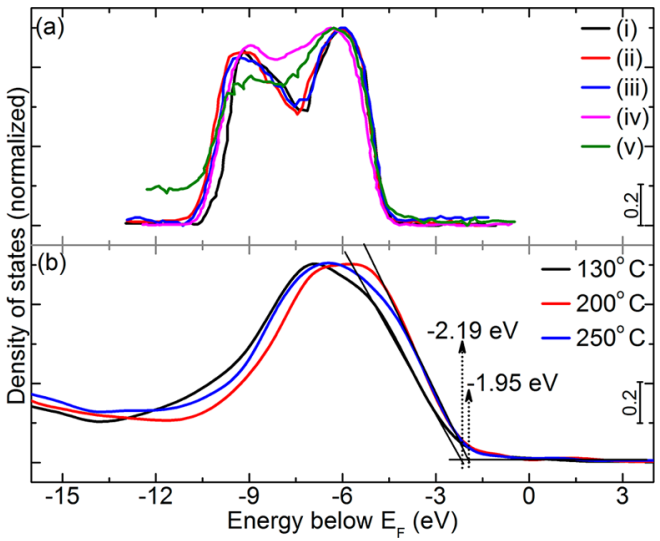

Figure 7. Selected region of the valence band: (a) data curves, (i), (ii), and (iii) were taken from ref 5 , while (iv) and (v) were taken from ref 6; and (b) magnified region of valence band spectra from the three samples.

from ref 5 that resulted from $\mathrm{LDA}, \mathrm{GW}_{0}$, and $\mathrm{G}_{0} \mathrm{~W}_{0}$ simulations, respectively. Data curves (iv) and (v) were taken from ref 6, which resulted from ab initio molecular dynamics (MD) simulation and experiment, respectively. In this $\mathrm{MD}$ simulation, $\mathrm{ZrO}_{2}$ is modeled as amorphous material. The valence edge regions of the present samples are magnified and shown in Figure $7 \mathrm{~b}$. The differences between Figure $7 \mathrm{a}$ and $\mathrm{b}$ are quite significant; VB minima are estimated to be $2.19 \mathrm{eV}$ for the $130{ }^{\circ} \mathrm{C}$ sample, while it is $1.95 \mathrm{eV}$ for the 200 and $250{ }^{\circ} \mathrm{C}$ samples. Apart from 
this, the Fermi edge is spanned ${ }^{30}$ for a relatively large energy range, which is explained in the following. Importantly, the two peaked feature (Figure 7a) originates from hybrid $\mathrm{O} 2 \mathrm{p}$ and $\mathrm{Zr}$ $4 \mathrm{~d}$ orbitals with a theoretical and experimentally observed width of $\sim 5 \mathrm{eV}^{5,13}$ It is interesting to note that these features are reproduced in the case of amorphous $\mathrm{ZrO}_{2}$, by theory and experiment; see data curves (iv) and (v), respectively. ${ }^{6}$ The hybridization of oxygen ( $2 \mathrm{p}$ ) and zirconium (4d) orbitals is crucial for the double-peaked structure. However, the surface composition influences the hybridization and subsequent structure from the spectroscopic point of view. For example, the $\mathrm{O}_{\mathrm{Ch}}$ is seen for all samples (Figure 4), while a high energy component is seen for the sample deposited at $130{ }^{\circ} \mathrm{C}$. Furthermore, we can see the metallic $\mathrm{Zr}$ of varying densities (Figure 5). The hybridized contribution from the metallic $\mathrm{Zr}$, chemisorbed oxygen, and $\mathrm{ZrO}_{2}$ most probably caused the broadening of the Fermi edge and less featured peak.

$\mathrm{ZrO}_{2}$ is quite often discussed and juxtaposed with $\mathrm{HfO}_{2}$ in the context of electronic structure in the literature. ${ }^{5,7} \mathrm{Zr}$ and $\mathrm{Hf}$ belong to the same group in the periodic table, but what differs in terms of the electronic structure is the f states. Furthermore, these elements are often regarded as the two chemically most similar homogenesis elements ${ }^{31}$ due to the well-known "lanthanide contraction". In the context of dissimilarity, $\mathrm{HfO}_{2}$ is more ionic and exhibits stronger crystal field effects than $\mathrm{ZrO}_{2}$ by giving the relatively smaller spectroscopic electronegativity of $\mathrm{Hf}(1.16$ vs 1.32 , ref 32$) .{ }^{7,33} \mathrm{HfO}_{2}$ together with $\mathrm{ZrO}_{2}$ are different from conventional sp semiconductors, especially with the structure of $\mathrm{CB}$, which exists between weakly correlated $\mathrm{sp}$ systems and highly complex strongly correlated $\mathrm{d}$ and f electron systems. Consequently, the similarity between $\mathrm{ZrO}_{2}$ and $\mathrm{HfO}_{2}$ both in LDA and GW is quite interesting. ${ }^{5}$

\section{EXPERIMENTAL SECTION}

Materials. Dimethylacetamide (DMAc) is used as a solvent for PES. All chemicals were used as received from Sigma-Aldrich. Tetrakis (dimethylamido) zirconium (TDMAZr) was procured from Sigma-Aldrich, and HPLC-grade deionized water was used in the ALD process.

Electrospinning. Uniform and bead-free PES nanofibers were produced via electrospinning. Please refer to Figure 1 (top) for the schematic diagram. The polymer solution consists of $45 \%$ $\mathrm{w} / \mathrm{v}$ of PES in DMAc. This mixture was stirred overnight at $60^{\circ} \mathrm{C}$ to obtain a homogeneous and clear solution. This solution was taken in a syringe fitted with a metallic needle of $\sim 0.8 \mathrm{~mm}$ of inner diameter. The syringe with solution then was fixed horizontally on a syringe pump (KD Scientific, KDS 101) with a feed rate of $1 \mathrm{~mL} / \mathrm{h}$. A $15 \mathrm{kV}$ high voltage is applied (Matsusada, AU Series) between the metal needle and a grounded electrode, which was kept at a distance of $\sim 15 \mathrm{~cm}$. Grounded electrode was wrapped with an $\mathrm{Al}$-foil to collect the fibers. The electrospinning process was carried out at $\sim 25^{\circ} \mathrm{C}$ and $36 \%$ relative humidity in an enclosed chamber.

ALD. The electrospun nanofibers were stabilized at $\sim 130$, 200, or $250{ }^{\circ} \mathrm{C}$ in a Savannah S100 ALD reactor (Cambridge Nanotech Inc.). TDMAZr was heated to $\sim 75^{\circ} \mathrm{C}$ and stabilized for 30 min prior to the depositions, whereas $\mathrm{H}_{2} \mathrm{O}$ was used when at room temperature. Depositions were carried out using the exposure mode (a trademark of Ultratech/Cambridge Nanotech Inc.) in which dynamic vacuum is switched to static vacuum just before each precursor pulse by closing the valve between the reaction chamber and the pump, allowing the substrate to be exposed to precursor molecules for a certain period of time (i.e., exposure time). This is followed by a purging period, where the chamber is switched back to dynamic vacuum for purging of excess precursor molecules and gaseous byproducts. $\mathrm{N}_{2}$ was used as a carrier gas at a flow rate of $\sim 20 \mathrm{sccm}$. $200 \mathrm{ZrO}_{2}$ cycles were deposited, where each cycle consists of the following steps: valve $\mathrm{OFF} / \mathrm{H}_{2} \mathrm{O}$ pulse $(0.015 \mathrm{~s})$ /exposure $(45,10,5 \mathrm{~s}) /$ valve $\mathrm{ON} / \mathrm{N}_{2}$ purge $(45,10,5 \mathrm{~s}) /$ valve OFF/TDMAZr pulse $(0.2,0.25,0.4 \mathrm{~s}) /$ exposure $(45,10,5 \mathrm{~s})$ /valve $\mathrm{ON} / \mathrm{N}_{2}$ purge $(45,10,5 \mathrm{~s})$.

Characterization. The morphologies of the samples were investigated using a SEM (FEI-Quanta 200 FEG). A nominal 5 $\mathrm{nm} \mathrm{Au} / \mathrm{Pd}$ alloy was sputtered onto the samples prior to the observation under SEM. For TEM imaging (FEI-Tecnai G2 F30), the samples were dispersed in ethanol, and the suspension was collected onto a holey carbon-coated TEM grid. XRD patterns were recorded $\left(2 \theta=10-80^{\circ}\right)$ by employing a PANalytical X'Pert Multi Purpose X-ray diffractometer with $\mathrm{Cu} \mathrm{K} \alpha$ radiation $(\lambda=1.5418 \AA)$. The ionic states of the surface elements were determined via XPS (Thermo Scientific, K-Alpha, monochromatic $\mathrm{Al} \mathrm{K} \alpha$ X-ray source, $400 \mu \mathrm{m}$ spot size, $h \nu=$ $1486.6 \mathrm{eV}$ ) in the presence of a flood gun charge neutralizer. For the core-level spectra, pass energy and step size were 30 and 0.1 $\mathrm{eV}$, respectively. Peak deconvolution of the photoelectron spectra was performed through Avantage software. The number of peaks is assigned in deconvolution depending on the chemistry of the material; however, their characteristics are allowed to vary.

\section{CONCLUSION}

The core and valence level electronic structures of $\mathrm{ZrO}_{2}$ coreshell nanostructures deposited at three different template temperatures were investigated. By varying the deposition temperature, control of the crystallinity is harnessed where a clear transition from amorphous to tetragonal $\mathrm{ZrO}_{2}$ is evidenced. The results of this study enhance the understanding of the evolution of various bands in the presence of $\mathrm{O}_{\mathrm{Ch}}$ and changes to the crystallinity. The presence and sustained fraction of $\mathrm{O}_{\mathrm{Ch}}$ is an indication of surface reactivity and defects such as $\mathrm{V}_{\mathrm{O}}$ 's. The $\mathrm{Zr} 3 \mathrm{~s}$ level from $130{ }^{\circ} \mathrm{C}$ sample appeared to slightly blue shift from its higher temperature counterparts, which might be due to surface heterogeneity from $\mathrm{O}_{\mathrm{Ch}}$ of various origins. Analysis on $\mathrm{Zr} 3 \mathrm{~d}$ indicated the presence of metallic-Zr $\left(\mathrm{Zr}^{+\zeta}, 0 \leq|\zeta|<4\right)$, the fraction of which decreases with increasing template temperature. On the other hand, the ALD parameters and characteristics of the substrate might influence the properties. The region close to $E_{\mathrm{F}}$ depicted features that are in contrast with the literature. Analysis of the VB region evidenced various differences attributed to complex hybridization of orbitals from chemisorbed species based on the analyses from $\mathrm{O} 1 \mathrm{~s}, \mathrm{Zr} 3 \mathrm{~d}$, and $\mathrm{Zr} 4 \mathrm{p}$ levels. The metallic- $\mathrm{Zr}$ on $\mathrm{ZrO}_{2}$ homocombination can have potential where the chemisorbed species including metallic- $\mathrm{Zr}$ determines the structure of $\mathrm{VB}$ and the electronic properties. To resolve the contribution of each of the components, a thorough computational study is perhaps useful.

\section{ASSOCIATED CONTENT}

\section{Supporting Information}

The Supporting Information is available free of charge on the ACS Publications website at DOI: 10.1021/acs.jpcc.5b07904.

Additional characterization, $\mathrm{Zr} 3 \mathrm{~s}$ spectra, and valence band region for two energy step sizes (PDF) 


\section{AUTHOR INFORMATION}

\section{Corresponding Authors}

*Tel.: +49 (30) 8413 5413. E-mail: svempati01@qub.ac.uk.

*Tel.: +90 (312) 290 3571. E-mail: uyar@unam.bilkent.edu.tr.

\section{Notes}

The authors declare no competing financial interest.

\section{ACKNOWLEDGMENTS}

S.V. thanks TUBITAK (TUBITAK-BIDEB 2221-Fellowships for Visiting Scientists and Scientists on Sabbatical) for the postdoctoral fellowship. F.K. thanks TUBITAK-BIDEB for a Ph.D. scholarship. N.B. thanks EU FP7-Marie Curie-IRG for funding NEMSmart (PIRG05-GA-2009-249196). T.U. thanks EU FP7-Marie Curie-IRG (NANOWEB, PIRG06-GA-2009256428) and The Turkish Academy of Sciences - Outstanding Young Scientists Award Program (TUBA-GEBIP) for partial funding. We thank Dr. Asli Celebioglu, UNAM, Bilkent University, for processing the XPS data.

\section{REFERENCES}

(1) Liu, J.; Meng, X.; Banis, M. N.; Cai, M.; Li, R.; Sun, X. Crystallinitycontrolled Synthesis of Zirconium Oxide Thin Films on Nitrogendoped Carbon Nanotubes by Atomic Layer Deposition. J. Phys. Chem. C 2012, 116, 14656-14664.

(2) Miikkulainen, V.; Leskela, M.; Ritala, M.; Puurunen, R. L. Crystallinity of Inorganic Films Grown by Atomic Layer Deposition:Overview and General Trends. J. Appl. Phys. 2013, 113, 021301.

(3) Gionco, C.; Livraghi, S.; Valentin, C. D.; Maurelli, S.; Pacchioni, G.; Giamello, E.; Tosoni, S. Al- and Ga-Doped $\mathrm{TiO}_{2}, \mathrm{ZrO}_{2}$, and $\mathrm{HfO}_{2}$ : The Nature of $\mathrm{O} 2 \mathrm{p}$ Trapped Holes from a Combined Electron Paramagnetic Resonance (EPR) and Density Functional Theory (DFT) Study. Chem. Mater. 2015, 27, 3936-3945.

(4) Cadi-Essadek, A.; Roldan, A.; de-Leeuw, N. H. Ni Deposition on Yttria-stabilized $\mathrm{ZrO}_{2}$ (111) Surfaces: A Density Functional Theory Study. J. Phys. Chem. C 2015, 119, 6581-6591.

(5) Jiang, H.; Gomez-Abal, R. I.; Rinke, P.; Scheffler, M. Electronic Band Structure of Zirconia and Hafnia Polymorphs from the GW Perspective. Phys. Rev. B: Condens. Matter Mater. Phys. 2010, 81, 085119. (6) Sayan, S.; Bartynski, R. A.; Zhao, X.; Gusev, E. P.; Vanderbilt, D.; Croft, M.; Holl, M. B.; Garfunkel, E. Valence and Conduction Band Offsets of a $\mathrm{ZrO}_{2} / \mathrm{SiO}_{\mathrm{x}} \mathrm{N}_{\mathrm{y}} / \mathrm{N}-\mathrm{Si}$ Gate Stack: A Combined Photoemission and Inverse Photoemission Study. Phys. Status Solidi B 2004, 241, 2246-2252.

(7) Zheng, W.; Bowen, J. K. H.; Li, J.; Dabkowska, I.; Gutowski, M. Electronic Structure Differences in $\mathrm{ZrO}_{2} \mathrm{Vs} \mathrm{HfO}_{2}$. J. Phys. Chem. A 2005, 109, 11521.

(8) Clarke, D. R.; Levi, C. G. Materials Design for the Next Generation Thermal Barrier Coatings. Annu. Rev. Mater. Res. 2003, 33, 383.

(9) Chen, G. H.; Hou, Z. F.; Gong, X. G.; Li, Q. Effects of Y-doping on the Structural Stability and Defect Properties of Cubic $\mathrm{HfO}_{2}$. J. Appl. Phys. 2008, 104, 074101.

(10) Kogler, M.; Kock, E. M.; Perfler, L.; Bielz, T.; Pollach, M. S.; Hetaba, W.; Willinger, M.; Huang, X.; Schuster, M.; Klotzer, B.; et al. Methane Decomposition and Carbon Growth on $\mathrm{Y}_{2} \mathrm{O}_{3}$, Yttria-stabilized Zirconia, and $\mathrm{ZrO}_{2}$. Chem. Mater. 2014, 26, 1690-1701.

(11) Fang, D.; Luo, Z.; Liu, S.; Zeng, T.; Liu, L.; Xu, J.; Bai, Z.; Xu, W. Photoluminescence Properties and Photocatalytic Activities of Zirconia: Nanotube Arrays Fabricated by Anodization. Opt. Mater. 2013, 35, $1461-1466$.

(12) Ushakov, S. V.; Navrotsky, A.; Yang, Y.; Stemmer, S.; Kukli, K.; Ritala, M.; Leskelä, M. A.; Fejes, P.; Demkov, A.; Wang, C.; et al. Crystallization in Hafnia and Zirconia-Based Systems. Phys. Status Solidi B 2004, 241, 2268.

(13) Soriano, L.; Abbate, M.; Faber, J.; Morant, C.; Sanz, J. M. The Electronic Structure of $\mathrm{ZrO}_{2}$ : Band Structure Calculations Compared to Electron and X-ray Spectra. Solid State Commun. 1995, 93, 659-665.
(14) Robertson, J. High Dielectric Constant Gate Oxides for Metal Oxide Si Transistors. Rep. Prog. Phys. 2006, 69, 327.

(15) Ito, T.; Maeda, M.; Nakamura, K.; Kato, H.; Ohki, Y. Similarities in Photoluminescence in Hafnia and Zirconia Induced by Ultraviolet Photons. J. Appl. Phys. 2005, 97, 054104.

(16) Samanta, A.; Zhang, S. B. Fluid Like Behavior of Oxygen in Cubic Zirconia under Extreme Conditions. Appl. Phys. Lett. 2012, 101, 181906.

(17) Youssef, M.; Yildiz, B. Predicting Self-Diffusion in Metal Oxides from Frst Principles: The Case of Oxygen in Tetragonal $\mathrm{ZrO}_{2}$. Phys. Rev. B: Condens. Matter Mater. Phys. 2014, 89, 024105.

(18) Aidhy, D. S.; Liu, B.; Zhang, Y.; Weber, W. J. Strain-induced Phase and Oxygen-Vacancy Stability in Ionic Interfaces from First-Principles Calculations. J. Phys. Chem. C 2014, 118, 30139-30144.

(19) Oldham, C. J.; Gong, B.; Spagnola, J. C.; Jur, J. S.; Senecal, K. J.; Godfrey, T. A.; Parsons, G. N. Encapsulation and Chemical Resistance of Electrospun Nylon Nanofibers Coated Using Integrated Atomic and Molecular Layer Deposition. J. Electrochem. Soc. 2011, 158, D549D556.

(20) Kayaci, F.; Vempati, S.; Donmez, I.; Biyikli, N.; Uyar, T. Role of Zinc Interstitials and Oxygen Vacancies of $\mathrm{ZnO}$ in Photocatalysis: A Bottom-up Approach to Control Defect Density. Nanoscale 2014, 6, 10224-10234.

(21) fwhm indicates the spread of the binding energy. Hence, a higher value implies a wide distribution of chemical environments.

(22) Naumkin, A. V.; Vass, A. K.; Gaarenstroom, S. W.; Powell, C. J. NIST X-ray Photoelectron Spectroscopy Database; U.S. Secretary of Commerce, 2012; Vol. NIST Standard Reference Database 20, Version 4.1.

(23) Kayaci, F.; Vempati, S.; Akgun, C. O.; Biyikli, N.; Uyar, T. Enhanced Photocatalytic Activity of Homoassembled ZnO Nanostructures on Electrospun Polymeric Nanofibres: A Combination of Atomic Layer Deposition and Hydrothermal Growth. Appl. Catal., B 2014, 156-157, 173-183.

(24) Chen, M.; Wang, X.; Yu, Y. H.; Pei, Z. L.; Bai, X. D.; Sun, C.; Huang, R. F.; Wen, L. S. X-ray Photoelectron Spectroscopy and Auger Electron Spectroscopy Studies of Al-doped ZnO Films. Appl. Surf. Sci. 2000, 158, 134-140.

(25) Major, S.; Kumar, S.; Bhatnagar, M.; Chopra, K. L. Effect of Hydrogen Plasma Treatment on Transparent Conducting Oxides. Appl. Phys. Lett. 1986, 49, 394.

(26) Ji, S.; Chang, I.; Lee, Y. H.; Park, J.; Paek, J. Y.; Lee, M. H.; Cha, S. W. Fabrication of Low-temperature Solid Oxide Fuel Cells with a Nanothin Protective Layer by Atomic Layer Deposition. Nanoscale Res. Lett. 2013, 8, 48.

(27) Liu, G.; Rodriguez, J. A.; Hrbek, J.; Dvorak, J.; Peden, C. H. F. Electronic and Chemical Properties of $\mathrm{Ce}_{0.8} \mathrm{Zr}_{0.2} \mathrm{O}$ (111) Surfaces: Photoemission, XANES, Density Functional, and $\mathrm{NO}_{2}$ Adsorption Studies. J. Phys. Chem. B 2001, 105, 7762-7770.

(28) Fuggle, J. C. Core-Level Binding Energies in Metals. J. Electron Spectrosc. Relat. Phenom. 1980, 21, 275-281.

(29) Ma, W.; Herbert, F. W.; Senanayake, S. D.; Yildiz, B. NonEquilibrium Oxidation States of Zirconium During Early Stages of Metal Oxidation. Appl. Phys. Lett. 2015, 106, 101603.

(30) Note that there is always a contribution from the energy-related instrument broadening. Better energy step size did not influence the features. See Figure S3 depicting two energy step sizes.

(31) Cotton, F. A.; Wilkinson, G.; Murillo, C. A.; Bochmann, M. Advanced Inorganic Chemistry; Wiley: New York, 2000.

(32) Li, W.-K.; Zhou, G.-D.; Mak, T. C. W. Advanced Structural Inorganic Chemistry; Oxford University Press: Oxford, 2008.

(33) Jaffe, J. E.; Bachorz, R. A.; Gutowski, M. Low-temperature Polymorphs of $\mathrm{ZrO}_{2}$ and $\mathrm{HfO}_{2}$ : A Density Functional Theory Study. Phys. Rev. B: Condens. Matter Mater. Phys. 2005, 72, 144107. 